\title{
Measurement of airborne radon concentrations at several sites in a radioactivity research laboratory
}

\author{
Masami Shimizu ${ }^{\S}$ and Ikuro Anzai ${ }^{\dagger}$ \\ ${ }^{8}$ Division of Radioisotope Research, Dental Research Center, Nihon University School of Dentistry, Tokyo 101-8310 \\ ${ }^{\dagger}$ College of International Relations, Ritsumeikan University, Kyoto 603-8577
}

(Received 30 September 1998 and accepted 30 April 1999)

\begin{abstract}
Radon-222 is a natural, gaseous, radioactive nuclide released from the ground and building materials into the air. Radon and its daughter nuclides can be an important disturbance factor for the measurement of environmental radioactivity. Radon concentrations in air in a radiation laboratory were measured with PICO-RAD detectors, which directly adsorb radon gas on activated charcoal. Generally, radon concentration increased in the absence of ventilation; a high concentration was observed in a radioisotope storage room without ventilation. Concentrations were low in other rooms used for experiments and measurement, which suggests that the radiation control practice in this laboratory is satisfactory and that the influence of natural radon gas on the measurement of radioactivity is negligible. (J. Oral Sci. $41,67-69,1999$ )
\end{abstract}

Key words: radon; natural radioactive nuclide;activated charcoal detector; radiation facilities; radon daughter.

\section{Introduction}

The need for more precise measurement of low-level environmental radioactivity has been increasing from the viewpoints of improving public safety and improving the quality of research in the field of radiological protection. Radon $\left({ }^{222} \mathrm{Rn}\right)$, a natural radioactive gas emanating from the ground and building materials, belongs to the uranium series and produces successive radioactive daughter nuclides through radioactive disintegrations emitting $\alpha, \beta$ and $\gamma$ rays. These radioactive nuclides increase the background radiation level, thereby disturbing measurements of low-level environmental radioactivity.

Although radon is an inert gas, radon daughters have a positive electric charge and float in the air by sticking to negatively charged aerosol dusts (1). Therefore, it is important for the measurement of radioactivity for both experiments

Correspondence to Masami Shimizu, Division of Radioisotope Research, Dental Research Center, Nihon University School of Dentistry, 1-8-13 Kanda-Surugadai, Chiyoda-ku, Tokyo 101-8310, Japan. and radiation control to evaluate the behavior of natural radionuclides in radiation facilities. There are two different methods of measurement, direct radon measurement and indirect determination through measurement of the daughter nuclides. In this study, PICO-RAD detectors were used to determine concentrations of radon and its daughter nuclides in air in the Radioisotope Research Laboratory, Nihon University School of Dentistry. In this method, radon is directly adsorbed on activated charcoal and measured with a liquid scintillation counter.

The concentration of airborne radon in a room depends on the wall materials, temperature and humidity, the operation of the ventilation system, and the concentration of suspended particles in the air. Consequently, to determine the average concentration in a specific facility, it is necessary to carry out measurements under different air conditions.

\section{Materials and Methods}

Radon was collected in activated charcoal vials (PICORAD vials) placed at each site to be monitored. The vial was uncapped to allow radon to diffuse into the charcoal and was recapped after $48 \mathrm{~h}$ in consideration of the half-life of ${ }^{222} \mathrm{Rn}$, which is 3.8 days.

After this, $10 \mathrm{ml}$ of InstaFluor scintillation cocktail (packard Instrument Co.) was added to each vial. After $4 \mathrm{~h}$, decays of radon and its daughter nuclides were continuously counted by a liquid scintillation system (Packard Tricarb 2000 CA, Packard Instrument Co.). The counting time was $5 \mathrm{~min}$ for each vial at a window width of $25-900 \mathrm{keV}$. We used the values obtained 8-10 h after the start of elution, because the counting levels reach a maximum, as shown in Fig. 1.

Measurements were done on a fine winter day with low humidity, because there are some indications that rainfall may cause exhalation and emanation of radon $(2,3)$.

Radon concentrations were measured at 16 different sites under different ventilation conditions: radiation control office, monitoring room, counting room, liquid scintillation counter, photographic darkroom, low-temperature room, tracer rooms 1 and 2, biological laboratory, animal breeding room, waste storage room, passage room, high level rooms 1 and 2, and radioisotope storage rooms 1 and 2 (Fig. 2).

The reliability of the PICO-RAD detector was checked by 


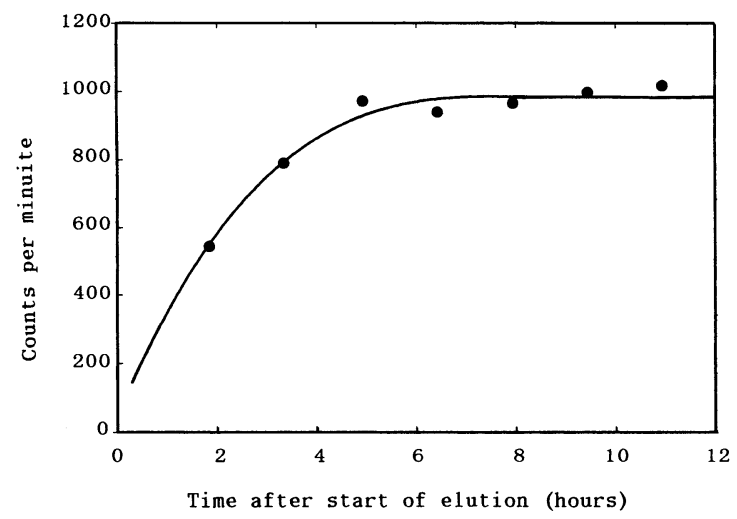

Fig. 1 Elution curve for PICO-RAD detector.

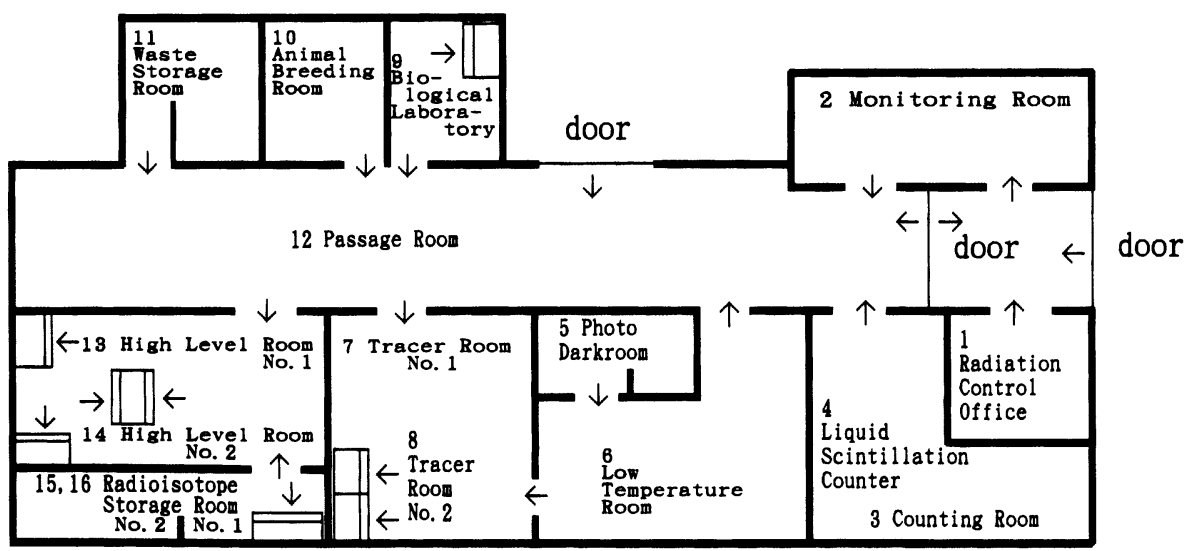

Fig. 2 Plane figure of radioactivity reseach facility in question. Arrows in the figure indicate prevailing wind direction at each point.

comparing the results from 7 detectors placed at the same point in a closed room without ventilation. As shown in Table 1 , the result of measurement was $588.5 \pm 20.6 \mathrm{cpm}$, a relative error of $3.5 \%$, which we considered adequate for the purpose of this study.

\section{Results}

Table 2 shows the radon concentrations measured at the 16 sites. Sites 1-15 are occupied frequently. Sites 3-5, 7-9, 13, and 14 are used mainly for experiments. Site 4 is where the samples were sent for liquid scintillation counting.

Radon concentrations were low at sites 1-14 when the ventilation system was in operation (mean $7.8 \mathrm{cpm}$ ) and higher when it was not (mean $17.9 \mathrm{cpm}$ ): ventilation reduced the concentration by $57 \%$. The effects of ventilation varied irregularly from place to place, depending not only on the structure of each room but also on the frequency of entrance.

Higher radon concentrations were observed in the radioisotope storage rooms, especially room 2 .

\section{Discussion}

A number of papers report seasonal variations in radon concentrations in air. Katsuya et al. (4) and Iida et al. (5) found that radon concentrations were higher in winter and lower in summer on the Pacific coast of Japan. Azini-Garakani reported no significant relationship between humidity and radon concentration in $90 \%$ of the data obtained (6). However, humidity is considered to influence the absorption efficiency of the activated charcoal (7) of PICO-RAD detectors. Kojima (2) and Stranden et al. (3) pointed out that the abundance of water in the air during rain also influences radon exhalation and emanation. This is why we took our measurements on a fine winter day with low humidity.

The main source of radon in the open air is emanation from the ground. Indoor radon is supplied mainly by the inflow of air with a high radon concentration from under the floor and the exhalation of radon from building materials used in floors, walls, and ceilings. The indoor concentration decreases when fresh air is supplied from outside. Consequently, the indoor radon concentration depends mainly on the ventilation (8) and the inflow of air from the ground. As shown in Table 2, the radon concentration was decreased by about half by the operation of the ventilation system from 9 a.m. to 5 p.m. on weekdays and from 9 a.m. to 1 p.m. on Saturdays. The values shown in the column "ventilator operating" in Table 2 were obtained from $48 \mathrm{~h}$ exposure on weekdays with the ventilator on for $16 \mathrm{~h}$ and off for $32 \mathrm{~h}$, whereas those in the column "ventilator not operating" were obtained by $48 \mathrm{~h}$ exposure on Saturday to Monday with the ventilator on for $4 \mathrm{~h}$ and off for $44 \mathrm{~h}$. Therefore, these results are a mixture of two different environmental conditions, which seems to be one reason why the decrease in radon concentration by operation of the 
Table 1 Results of measurement of 7 PICO-RAD detectors placed at the same point (cpm)

\begin{tabular}{cc} 
No. & Measured Values \\
& \\
\hline 1 & 558.7 \\
2 & 615.0 \\
3 & 565.7 \\
4 & 584.7 \\
5 & 591.3 \\
6 & 597.0 \\
7 & 607.0 \\
\hline & \\
Average & $588.5 \pm 20.6$ \\
\hline
\end{tabular}

ventilation system was not dramatic.

If exposure to a lower radon environment for $1 \mathrm{~h}$ results in $\alpha \mathrm{cpm}$ and exposure to a higher radon environment for $1 \mathrm{~h}$ results in $\beta \mathrm{cpm}$, then the measured values $\mathrm{X}$ and $\mathrm{Y}$ cpm under the conditions described above can be expressed as follows:

$$
\mathrm{X}=16 \alpha+32 \beta, \mathrm{Y}=4 \alpha+44 \beta
$$

For example, at measurement site 10 , the animal breeding room, $\mathrm{X}=11$ and $\mathrm{Y}=14$. Therefore, $\alpha=0.063$ and $\beta=0.31$. This analysis seemed to be effective at extracting the influence of ventilation from complicated conditions, but we soon saw that the results did not show any consistent relationship, even giving negative values for $\alpha$ in some cases. This indicates that the measured values depend not only on the operation of the ventilation system but also on more complicated factors such as occupancy and the frequency and duration of door opening.

The radon concentration at site 16 was extremely high, partly because the room was used for storing radioisotopes and partly because it has a thick wall for radiation shielding, which emits radon gas. Site 16 is a small airtight compartment behind site 15 . It has a low occupancy factor and does not have its own ventilation system.

Radon concentrations in rooms 1-14 under ventilation were within twice the background level. Even without ventilation, approximately half of the measured values did not exceed twice the background level. Such low levels of radon do not have any significant effect on ordinary measurement except where low-level radiation must be determined accurately. Thus the influence of airborne radon on the accuracy of measurement is negligible for the purpose of experiments carried out in this facility.

\section{References}

1. Ohta, Y. (1993) A survey of indoor radon and particulate concentration. Radioisotopes 42, 461-466 (in Japanese)

2. Kojima, H. (1987) Meteorological factors influencing
Table 2 Airborn radon concentrations at the sites in a radiation facility $(\mathrm{cpm})$

\begin{tabular}{|c|c|c|}
\hline \multirow{2}{*}{ Measurement Points } & \multicolumn{2}{|c|}{ Measured Values } \\
\hline & Ventilation Operating & Ventilation Not \\
\hline 1 Radiation Control office & $8.4 \pm 2.3$ & $12.2 \pm 2.3$ \\
\hline 2 Monitoring Room & $8.2 \pm 2.3$ & $24.4 \pm 2.8$ \\
\hline 3 Counting Room & $11.2 \pm 2.4$ & $16.4 \pm 2.5$ \\
\hline \multicolumn{3}{|l|}{4 Liquid Scintillation } \\
\hline Counter & N.D. & $19.0 \pm 2.6$ \\
\hline 5 Photo Darkroom & $8.0 \pm 2.2$ & $14.4 \pm 2.4$ \\
\hline 6 Low Temperature Room & $6.6 \pm 2.2$ & $16.2 \pm 2.4$ \\
\hline 7 Tracer Room No. 1 & $7.8 \pm 2.2$ & $22.2 \pm 2.7$ \\
\hline 8 Tracer Room No. 2 & $8.8 \pm 2.3$ & $14.8 \pm 2.4$ \\
\hline 9 Biological Laboratory & $10.4 \pm 2.4$ & $19.0 \pm 2.5$ \\
\hline 10 Animal Breeding Room & $11.0 \pm 2.4$ & $14.0 \pm 2.4$ \\
\hline 11 Waste Storage Room & $8.0 \pm 2.2$ & $21.4 \pm 2.6$ \\
\hline 12 Passage Room & $12.4 \pm 2.4$ & $14.0 \pm 2.4$ \\
\hline 13 High Level Room No. 1 & N.D. & $20.8 \pm 2.6$ \\
\hline 14 High Level Room No. 2 & $8.0 \pm 2.2$ & $21.8 \pm 2.7$ \\
\hline \multicolumn{3}{|l|}{15 Radioisotope Storage } \\
\hline Room No.1 & $16.6 \pm 2.6$ & $36.6 \pm 3.2$ \\
\hline \multicolumn{3}{|l|}{16 Radioisotope Storage } \\
\hline Room No. 2 . & $930.5 \pm 13.8$ & $1019.2 \pm 14.4$ \\
\hline$\star$ Background & $11.4 \pm 1.1$ & $9.0 \pm 1.0$ \\
\hline
\end{tabular}

*Background levels were measured by counting unused PICO-RAD detector vial filled with Instafluor scintillation cocktail.

on the radon concentrations in indoor and outdoor airs. Radon in the living environment-levels and risks. Proceedings of the 15th NIRS Seminar, held at Chiba, 3-4 December, 1987, 105-113 (in Japanese)

3. Stranden, E., Kolstad, A.K. and Lind, B. (1984) The influence of moisture and temperature on radon exhalation. Rad. Pro. Dos. 7, 55-58

4. Katuya, M., Ibuki, Y., Goto, R., Matsumoto, M. and Fujitaka, K. (1997) Measurement of outdoor radon concentrations in shizuoka prefecture. Radioisotopes 46, 427-438 (in Japanese)

5. Iida, T., Ikebe, Y. and Yamanishi, H. (1) Measurement of mean radon concentrations in the tokai districts. Radon in the living environment-levels and risks. Proceedings of the 15th NIRS Seminar, held at Chiba, 3-4 December, 1987, 43-54 (in Japanese)

6. Azimi-Garakani, D. (1993) An intercomparison of different passive radon detectors, Nucl. Tracks Radiat. Meas. 22, 259-262

7. Bocanegra, R. and Hopke, P.K. (1988) Radon adsorption on activated carbon and the effect of some airborne contaminants, Sci. Total Environ. 76, 193-202

8. Ikeda, K. (1987) The relation between ventilation rates and building structures. Radon in the living environmentlevels and risks, Proceedings of the 15th NIRS Seminar, held at Chiba, 3-4 December, 1987, 114-123 (in Japanese) 